\title{
Factors Influencing Clients' Compliance with Therapy of Tuberculosis in Ibadan, Nigeria
}

\author{
Oladeji Oloyede Michael Rn, *Tijani Wakili Adelani Rn, Bello Yisau Aderemi \\ Rn, Hamid Oluyedun, B.Pharm, Prefa Victor Rn, \\ MSc FWACN Lecturer Department of Nursing Ladoke Akintola University of Technology, Ogbomoso NIGERIA \\ PhD, FWACN Senior Lecturer Department of Nursing Ladoke Akintola University of Technology, Ogbomoso \\ Nigeria \\ BSc, MPP, MSN Clinical Instructor VA Medical Centre, Morcon College, USA \\ MSc, FWACP Deputy Director of Pharmaceutical Services Mininstry of Health, Oyo State \\ MBBS, Bls. Senior Medical Officer Niger Delta University Teaching Hospital Okolobiri Yenagoa Bayelsa State, \\ Nigeria.
}

\begin{abstract}
The study was carried out to investigate factors influencing clients' compliance with treatment of tuberculosis in Ibadan. The study was descriptive with a sample size of 212 randomly selected from three health centres. Sample selection were as follows: 50 respondents at the Catholic Hospital, Oluyoro; 67 at the Primary Health Care, Oniyanrin and 90 at the Chest Hospital, Jericho. The mean age of the respondents was $32 \pm$ 11.67. Males were $69.8 \%$ and female $30.2 \%$ with majority being Yorubas (59.9\%) and Christians (76.9\%) while as much as $61.3 \%$ were married. Educational status of the respondents showed only $19.8 \%$ possess bachelor degree, the rest others were school certificates (34.4\%) and national diploma (15.6\%) holders. As much as $33.5 \%$ of the respondents were unemployed, $24.5 \%$ Civil Servants and only 1.9\% were self employed. On the respondents' knowledge of tuberculosis, majority (83.5\%) of them knew tuberculosis as an infection of respiratory system, $85.9 \%$ knew it is caused by germ and $94.8 \%$ of them were aware it could be spread to other people through living in overcrowded places. All the respondents (100\%) experienced coughing that lasted over four weeks before reporting in the hospital where tuberculosis was diagnosed. On the expected duration of cure of tuberculosis, majority (82\%) of the respondents were aware that their ailment could take up to two years before they could get cured. They were however encouraged to comply with the treatment as $92.5 \%$ of them acknowledge the government largess in providing free treatment. The friendly attitude of the health personnel (without discrimination based on their health status) - 90.1\%, and coupled with failure of traditional treatment earlier sought before reporting in the orthodox hospital (76\%), further encouraged the respondents to comply with treatment. Two hypotheses were tested. The results of the first hypothesis showed that there was a significant association between the respondents' knowledge and their compliance with tuberculosis treatment regimen. The result of the second hypothesis revealed that there was no significant association between the respondents' social stigma and their compliance with tuberculosis treatment regimen. It was therefore recommended that the Damien's Foundation, with collaboration of the Federal Government, should continue to provide free treatment of tuberculosis until the disease ceased to be public health problem in Nigeria.
\end{abstract}

Key concept: Clients, Compliance, Therapy, Tuberculosis, Stigmatization

\section{Introduction}

Tuberculosis is one of the leading infectious diseases responsible for high rate of death globally. Tuberculosis kills someone approximately every 20 seconds and nearly 4,700 people every day. According to the latest estimates from the World Health Organization Global TB Control report (2010), in 2009 alone 1.7 million people died of tuberculosis. The report rated tuberculosis as second only to human immunodeficiency virus as the leading infectious killer of adults worldwide. It is among the three greatest causes of death of women aged 15 - 44. WHO (2005) discovered that tuberculosis kills 5000 people daily across the globe with $98 \%$ of death occurring in developing world and this affected mostly young adult in their most productive years. Nigeria ranked fourth among 22 burden countries for tuberculosis in the world. WHO (2006) reported that a total of 450,000 new cases occur yearly. In Nigeria, the National Tuberculosis and Leprosy Control Programme - NTLCP (2002) stated that a total of 86,241 of all forms of tuberculosis were notified from 36 states in 2007. NTLCP (2002) observed that tuberculosis has been steadily increasing over the years. The annual risk of infection is between $1-2 \%$. It is estimated that about 200,000 of tuberculosis cases occur annually in Nigeria, of which $50 \%$ are smear-positive. The national programme detected and treated 26,641 cases while $17 \%$ of tuberculosis cases were also patients that are HIV positive. Johansson et al (1999) also observed that, tuberculosis, after many years of decline in incidence, has once again started to increase 
worldwide. The reported male to female ration based on passive case finding is 2:1 and suggests differences in health services accessibility. Poor compliance with tuberculosis treatment has repeatedly been cited as one of the major obstacles in tuberculosis control.

There are ample evidences to support that non compliance of patients to treatment is the major problem in tuberculosis control. World Health Organization had devised different methods to promote compliance to treatment of tuberculosis and this include in-built monitoring system, pill counts, combination of tablets, blister packs, urine tests, hospitalization and supervised therapy. Furthermore, directly observed therapy was introduced to a number of chest clinics to promote compliance. This method entails nurses delivering anti tuberculosis drugs to the patient and observing the patient ingesting the drug. Erhabor et al. (2000) stated that the category of treatment did not significantly influence the rate of compliance of the patient despite the availability of anti tuberculosis drugs. Tuberculosis treatment programmes in most developing countries have not succeeded because of poor patient compliance with therapy, emergence of drug - resistant organisms and failure to carefully control drug supplies and therapy. Presently the cure rates in developing countries are frequently less than 50\%; however, cure rates of greater than $90 \%$ can be achieved when short course chemotherapy regimens are given under supervision. Sabate (2003) was of the view that tuberculosis is the most common infectious disease that represents a major public health threat to global population. The report observed that up to 8million new cases and 2.3 million deaths are attributed to tuberculosis infection annually due to multi drug resistance and non compliance to treatment.

Silvio (2005) believed that control of tuberculosis could be planned and implemented at primary, secondary and tertiary level of prevention. Primary prevention includes basic health promotion to limit susceptibility to disease. There should be good nutrition and effort to relieve conditions of poverty and improved living conditions. It also includes measures to improve ventilation and ultraviolet light in areas in which aerosol sputum specimens are collected; also in area where immunization and Chemoprophylaxis are administered. Secondary Prevention includes screening, diagnosis and treatment of existing disease. Tertiary prevention efforts are focused on three areas which includes preventing recurrence of the disease in the individual; notifying the appropriate health centre; and treating contact of cases of tuberculosis and isolation of infected person as needed.

Tuberculosis coalition for technical assistance, as observed by Stanhope and Lancaster (2000) viewed relapse as a state in which a patient first improves while on treatment but becomes ill again after stopping treatment. The study then view relapse of tuberculosis among adults worldwide as the leading cause of death from single infectious agent. It was observed that the incidence of tuberculosis in the United States showed a steady decline during the 1970s and early 1980s but began to increase again in 1989. The increase is believed to have been due to the growing incidence of tuberculosis in the following group of people; people living with HIV-AIDS, homeless, substance abusers, the elderly, immigrants, people in nursing homes and correctional facilities. In the study it was further discovered that in the development of multi drug resistance cases, the clients exhibited mortality rates of $43 \%$ to $89 \%$. The peak of relapse was in 1992 and this was observed among the foreign born persons. Tuberculosis continues to cause a large burden of disease in the world. To control the further spread of tuberculosis, the World Health Organization has put in place many strategies in order to achieve $85 \%$ of treatment success. It was observed that the challenges been faced by WHO strategies are behavioural in nature. The clients' behaviour in terms of self administration of drugs, treatment adherence and completion of treatment needs modification. Also knowledge and delayed diagnosis of tuberculosis. These challenges were observed to be prevalent in the three selected health care facilities. There has been increase in relapse case of patients based on hospital records; client commencing treatment and failed to complete treatment and reporting back to the hospital. Therefore, this study tends to investigate factors influencing client's compliance with treatment of tuberculosis in selected health centres in Ibadan.

\section{Health Belief Model}

Health belief model assumes that the beliefs and attitudes of people are critical determinants of their health related behaviour. The health belief model was first developed in the 1950s by Social psychologists, Hochbaum, Rosenstock and Kegels (Becker, 1985). Dracup and Meleis (1982) address the relationship between a person's beliefs and behaviours. It provides a way of understanding and predicting how clients will behave in relation to their health and how they will comply with health care therapies. The health belief model is a model based on the perceptions of the individual in any given health situation. The model states that an individual will take action to avoid health problem if he feels threatened. Threat is composed of three components; first, the person must perceive he is susceptible that is he believes that he personally has a reasonable chance of acquiring the health problem. Secondly, the individual perceives the severity of health problem, that is, in event of the problem occurring it would have a moderate or severe impact on his life. The third component is that the likelihood that a person will take preventive action result from the person's perception of the benefits and barriers to taking action. The preventive action may include life style changes, increased adherence to medical 
therapies, or a search for medical advice or treatment. A client's perception of susceptibility to disease will help to determine the likelihood that the client will or will not partake in healthy behaviours.

\author{
Hypotheses \\ 1 There is no significant association between clients' knowledge and compliance to tuberculosis \\ treatment \\ 2 There is no significant association between clients' stigmatization and compliance of tuberculosis \\ treatment.
}

\title{
II. Materials and Methods
}

The study is descriptive, and was carried out in the government Chest hospital Jericho, Primary health care, Oniyanrin and Catholic hospital all within Ibadan city. These centres are known for treatment of tuberculosis in Ibadan. The target population consists of diagnosed clients with tuberculosis who reported at the clinics. The record of admitted cases of tuberculosis from year 2000 to 2010 showed that the year 2008 recorded the highest number of diagnosed clients with tuberculosis in each of the centre. In 2008, Oluyoro Catholic hospital had 31, Primary health care, Oniyanrin recorded 384 cases while the Jericho Chest hospital had 517, making a total of 1213. Out of this figure, 212 that gave their informed consent were chosen as sample size, with an average of 67 cases per centre. A self developed instrument was used and this includes self report and structured questionnaire that assessed the socio-demographic characteristics of the subjects. The questionnaire contained 29 items and it consisted of three sections namely: Section A (respondents' characteristics), section B (respondents' knowledge on tuberculosis) and Section C (factors influencing respondents' compliance with treatment). The last section is D (level of compliance with treatment). With the Cronchbach's alpha estimate of 0.74 , the reliability of the instrument was determined. The data obtained was analyzed using the Statistical Package for Social Sciences (SPSS) version 11 and Ms-Excel.

\section{Results}

A sample of 212 tuberculosis patients was used and all were administered questionnaire with a 100\% response rate. Figure 1 shows the selection ratio among the three study centre.

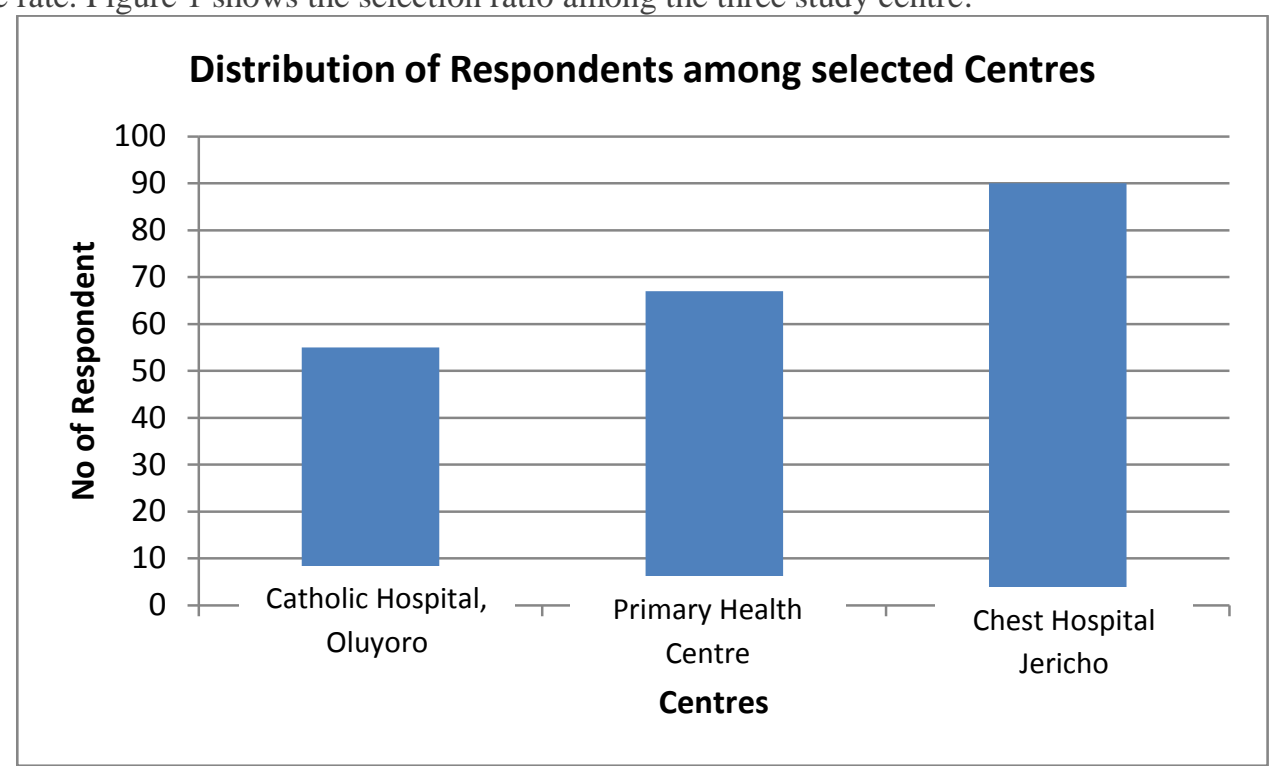

Demographic variables showed that the respondents' age ranges from 15-64 with a mean $32 \pm 11.67$. Females were $69.8 \%$ and male $30.2 \%$ with majority being Yorubas $(59.9 \%)$ and Christians $(76.9 \%)$ while as much as $61.3 \%$ were married. Educational status of the respondents showed only $19.8 \%$ possess school certificate, $34.4 \%$ were primary school leaving certificate holders while the rest $45.8 \%$ had no formal education. As much as $33.5 \%$ of the respondents were unemployed, $24.5 \%$ junior civil servants and only $1.9 \%$ were self employed.

On the respondents' knowledge of tuberculosis, majority $(83.5 \%)$ of them knew tuberculosis as an infection of respiratory system, $85.9 \%$ knew it is caused by germ and $94.8 \%$ of them were aware it could spread to among people through living in overcrowded places. All the respondents $(100 \%)$ experienced coughing that lasted over four weeks before reporting in the hospital where tuberculosis was diagnosed.

On the expected duration of cure of tuberculosis, majority $(82 \%)$ of the respondents were aware that their ailment could take up to two year before they could get cured and they were ready to endure till they get cured. They were however encouraged to comply with the treatment as $92.5 \%$ of them acknowledge the 
government largess in providing free treatment. The friendly attitude of the health personnel (without discrimination based on their health status) $-90.1 \%$ and coupled with failure of traditional treatment earlier sought before reporting in the orthodox hospital (76\%), further encouraged the respondents to comply with treatment.

Table 1 shows respondents' level of compliance with treatment regimen.

Table 1: Compliance with Treatment $(\mathrm{N}=212)$

\begin{tabular}{|c|c|c|c|c|}
\hline QUESTION & $\begin{array}{c}\text { Always } \\
\text { F(\%) }\end{array}$ & $\begin{array}{c}\text { Sometimes } \\
\text { F }(\%)\end{array}$ & $\begin{array}{c}\text { Rarely } \\
\text { F(\%) }\end{array}$ & $\begin{array}{l}\text { Never } \\
\text { F(\%) }\end{array}$ \\
\hline Do you miss your appointment with the & - & - & $42(19.8 \%)$ & $170(80.2 \%)$ \\
\hline \multicolumn{5}{|l|}{ doctor? } \\
\hline $\begin{array}{l}\text { Do you consider that medical advice is an } \\
\text { important aspect of your treatment? }\end{array}$ & $187(88.2 \%)$ & $25(11.8 \%)$ & - & - \\
\hline $\begin{array}{l}\text { Have you ever been diagnosed and never return } \\
\text { for treatment? }\end{array}$ & $18(8.5 \%)$ & $42(19.8 \%)$ & $19(9.0 \%)$ & $133(62.7 \%)$ \\
\hline $\begin{array}{l}\text { Have you ever started treatment before and did } \\
\text { not continue with the treatment? }\end{array}$ & - & - & - & $212(100.0 \%)$ \\
\hline $\begin{array}{l}\text { Have you ever been transferred from your } \\
\text { previous place of treatment to another place } \\
\text { and you failed to continue treatment due to } \\
\text { your work schedule? }\end{array}$ & - & - & - & $212(100.0 \%)$ \\
\hline Do you find taking your drug palatable? & $20(9.4 \%)$ & $171(80.7 \%)$ & - & $21(9.9 \%)$ \\
\hline $\begin{array}{l}\text { Do you experience drug reactions that } \\
\text { discourage you from continuing with } \\
\text { treatment? }\end{array}$ & - & $85(40.1 \%)$ & $21(9.9 \%)$ & $106(50.0 \%)$ \\
\hline
\end{tabular}

\section{Hypothesis testing}

Table 2 shows hypothesis I.

Table 2: Chi-square table for testing association between clients' knowledge and compliance to tuberculosis treatment

\begin{tabular}{|c|c|c|c|c|c|c|}
\hline & \multicolumn{2}{|c|}{ Knowledge } & \multirow[t]{2}{*}{ Total } & \multirow{4}{*}{$\begin{array}{l}\text { d.f } \\
1\end{array}$} & \multirow{3}{*}{$\begin{array}{l}\text { Chi-square } \\
18.54\end{array}$} & \multirow{3}{*}{$\begin{array}{l}\text { Sig. } \\
<.05\end{array}$} \\
\hline & Adequate & Inadequate & & & & \\
\hline Compliance & 124 & 68 & 192 & & & \\
\hline Non compliance & 3 & 17 & 20 & & & \\
\hline Total & 127 & 85 & 212 & & & \\
\hline
\end{tabular}

From the table, chi-square calculated is greater than chi-square tabulated with the degree of freedom 1 . The null hypothesis was therefore rejected. This indicates that there was a significant association between the respondents' knowledge and their compliance with tuberculosis treatment.

Hypothesis II: There is no significant association between clients' stigmatization and compliance of tuberculosis treatment.

Table 3: Chi-square table for testing association between clients' social stigmatization and compliance

\begin{tabular}{|c|c|c|c|c|c|c|}
\hline 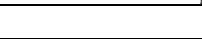 & \multicolumn{2}{|c|}{ Social stigmatization } & Total & d.f & Chi-square & Sig. \\
\hline & Positive & Negative & & & & \\
\hline Compliance & 153 & 39 & 192 & 1 & 0.001 & $>.05$ \\
\hline Non compliance & 16 & 4 & 20 & & & \\
\hline Total & 169 & 43 & 212 & & & \\
\hline
\end{tabular}

$$
\chi_{\text {cal }}^{2}=0.001 \quad \text { d.f. }=1, \quad \chi_{\text {tab }}^{2}=3.84 \quad \mathrm{P}>0.05
$$

Table 3 shows chi-square calculated is less than chi-square tabulated with the degree of freedom 1 . The null hypothesis is therefore rejected. This indicates that there was no significant association between the respondents' social stigma and their compliance with tuberculosis treatment. 


\section{Discussion}

According to the WHO (2010), 1.7 million people died of tuberculosis globally in 2009. It also observed that tuberculosis kills at least a person every 20 seconds and 4700 people every day through its spreading among people of poor socio-economic status in the world. However, Akinkugbe and Falase (2004) observed that tuberculosis patient under treatment constitutes no more danger to the society. The results of the present study corroborate this observation as the disease was not found to spread among the relatives and coinhabitants of the respondents. $98.9 \%$ of the respondents said the disease was limited to them since the time they have been receiving treatment in the hospital.

It was discovered that $69.8 \%$ of the study sample were female compared to $30.2 \%$ male. Male to female ratio is $>1: 2$. The increase in female proportion might be due to higher cultural responsibility the society placed on female than their male counterpart. Johansson et al. (1999) and Holmes et al.(1998) observed some factors contributing to gender inequality in tuberculosis infection and these include higher gender role for female; low prioritization of women's health; poverty which affects female more in patriarchal society; poor health service provision for women. In developing countries like Nigeria, most of these factors may propel the female gender to have higher percentage in the spread of tuberculosis. Similar findings were observed in the work of Vorokhobkin (2005). Female were found to be infected with tuberculosis at a rate thrice that of male. Tuberculosis has been found to spread more in overcrowded places such as living rooms, markets, schools and poorly ventilated places. According to Suzanne et al. (2007) and Park, (2009) tuberculosis has been found to spread mostly among people of poor socio-economic status. The results of the present study are in line with this discovery as married respondents (61.3\%) were more than singles (29.7\%). Also, percentage of respondents with poor educational status (47.6) was found to be higher than respondents with up to and above school certificate level $(12.7 \%)$. Likewise, unemployed respondents in the study were $87.1 \%$. It is clear that the respondents were affected by the disease since they could not afford good diet that could have improved their resistance to diseases. Also from the study, it was discovered that $92.5 \%$ of the respondents complied with treatment regimen because the treatment of tuberculosis is free. If the subjects were to pay just like in other ailments, the level of compliance might not be up to the recorded level. This is in consonance with the findings in Buchanam (1997) where it was discovered that provision of various forms of incentives encouraged larger number of tuberculosis patients to comply with treatment regimen. The free treatment is a form of incentives for the subjects. Most of the subjects would not have turn up for treatment and would have constituted great danger to the society if the National Tuberculosis and Leprosy Control Programme (NTLCP) as well as the Damien's Foundation have not worked together to reduce tuberculosis burden on the nation. Damien's Foundation provides free treatment while the NTLCP increases people's awareness on cardinal signs of tuberculosis. Unemployed individual could not afford to pay for treatment and would have continued to spread the disease among the populace before they either die or recover from the disease. This therefore indicates that the prevalence of tuberculosis in most developing countries is due to poverty.

The study also assessed the respondents' compliance with treatment regimen. $80.2 \%$ of the respondents said they never missed keeping appointment with doctor while $88.2 \%$ of them used to comply with medical advice and they $(81.2 \%)$ used to put into practice always the knowledge gained in health education to improve their health status. On the attitude and dexterity of health personnel, $90.1 \%$ of the respondents indicated that the medical personnel, showed concern for them and great dexterity in their job. Also, 63\% respondents were particularly grateful to the nurses that used to encourage them to take their daily drugs in their (the nurse) presence. Without the nurse encouragement on daily intake of the anti-tuberculosis drugs, $45 \%$ respondents said they could not have taken the drug regularly on their own accord. This, $44 \%$ of them observed, would have delayed the improvement in their health status. On the drug adverse reactions, $40.1 \%$ said they had not experience any serious adverse reaction and the little problem they had at initial stage of their drug intake were ameliorated by the health personnel. The empathy and the dexterity of the health personnel, observed by $87.4 \%$ of respondents, contributed immensely to their improvement. The concern and passion for welfare of clients as well as maintenance of professional ethics of health personnel do contribute immensely to aid clients' compliance with treatment and recovery (Norma, 1978).

From the study, $79.7 \%$ of the respondents did not want people to know that they were tuberculosis patients for fear of stigmatization. Majority of respondents (67\%) said they did not encourage their neighbour to come to the hospital to 'greet' them because they did not disclose their ailment to people outside their family members. Stigmatization is a major cause of spread of tuberculosis in most communities because most clients do not want to report in hospital for fear of the stigmatization among the relatives. Johansson et al. (1999) were of the view that stigmatization deters people from seeking care and diagnosis. They further reiterated that stigmatization is perpetrated by family members and sometimes reinforced by health personnel.

The chi-square test for the first hypothesis indicated that there was a significant association between the respondents' knowledge and their compliance with tuberculosis treatment. Park (2009) identified knowledge as an important factor that helps the host of tuberculosis to control the spread of the disease. It was further stated 
that the propensity to seek care depends on knowledge and perceived risk of tuberculosis within the reference groups and communities at large and this has assisted in compliance with treatment.

The second hypothesis tested significant association between stigmatization and compliance to treatment. The results of the chi-square test showed that there was no association between stigmatization and compliance with treatment regimen. The respondents though fear stigmatization, did not give room for people to stigmatize them as they limited the knowledge of their ailment (tuberculosis) to only their immediate family. Therefore, there was no stigmatization that could affect their compliance to treatment regimen.

\section{Conclusion and Recommendation}

It was discovered that the subjects' compliance to treatment was based on the largess of the Damien's Foundation and the Nigeria government in providing free treatment. The friendly attitude of the health personnel was also acknowledged as the contributory factor to their compliance. The subjects praise the nondiscriminatory efforts of the health personnel in their recovery. They were encouraged to complete their treatment as no one stigmatized them among other patients within the hospital.

It is therefore recommended that the free treatment and the acknowledged professionalism of the health personnel should continue till tuberculosis disease is eradicated or at least is drastically reduced.

\section{Acknowledgement}

The research team appreciates the cooperation of the subjects and the permission granted for carrying out the study by the authorities of the health facilities used.

\section{References}

[1]. World Health Organization (2010): Global Tuberculosis Control Report

[2]. World Health Organization (2005): Global Project on Anti Tuberculosis Drug Resistance. Surveillance

[3]. World Health Organization (2006): Global Tuberculosis Control Report. 1 -10

[4]. National Tuberculosis and Leprosy Control Programme manual (2002) Nigeria

[5]. Johansson, E. Long, N.H, Diwan, V.K, Winikvist, A. (1999) Attitude to Compliance with Tuberculosis Treatment among Women and Men in Vietman. International Tuberc Lung Dis. 3(10): $862-868$

[6]. Erhabor, Aghanwa, Yusuph, Adebayo, Arogundade and Omidiora (2000): Factors Influencing Compliance in Patients with Tuberculosis on Directly Observed Therapy, Ile Ife, Nigeria

[7]. Sabate, E. (2003): Adherence to Long Term Therapies: Evidence for Action. World Health Organization. Geneva. 212

[8]. Silvio Waisbord (2005): Behavioural Barriers in Tuberculosis Control MEDLINE

[9]. Stanhope, Marcia and Lancaster, Jeanett (2000): Community and Public health nursing. 5 th edition, Mosby U.S.A. 494 - 496

[10]. Becker MH (1985). Patient adherence to prescribed therapies. Medical care 23: 539-555

[11]. Dracup K \& Meleis AI (1982). Compliance: an interactionist approach. Nursing Research 31 (1): 31-36

[12]. Falase, A.O. and Akinkugbe (1999): A Compendium of Clinical Medicine Spectrum Publishers, Ibadan page 152 - 157

[13]. Holmes, CB. Hausler, H. Nunnm P. (1998): A Review of Sex differences in the epidemiology of tuberculosis. Tuberculosis Research and Surveillance unit, Global Tuberculosis Programme, WHO Geneva, Switzerland

[14]. Vorokhobkin Lus (2005): Age-sex-related and Social characteristics of Patients with New-Onset Tuberculosis in urban and rural areas. Pubmed 642 records Prob\Tuberk Bolezn legk(12): 26 - 9 World Health Organization (2008) reports

[15]. Suzanne, C. Brenda, G. Janice, L. and Kerry, H (2007): Brunner and Suddarth's Textbook. Medical - Surgical Nursing, $11^{\text {th }}$ edition Lippincott Williams and Wilkins, London

[16]. Park, K (2009): Park's Textbook of Preventive and Social Medicine, $20^{\text {th }}$ edition. Jabalpur, India

[17]. Buchanam, Robert. J. (1997): Compliance with Tuberculosis Drug Regimen: Incentives and Enablers offered by Public Health Department. American Journal of Public health Vol. 89, No 12 page 2014 - 2017

[18]. Norma L Chaska (1996): Nursing Profession: Views Through the Mist, London, ELBS 